\title{
Gemeinschaft in und vor dem Bild
}

Claudia Blümle

Inmitten einer dicht gedrängten Gruppe männlicher Personen vollzieht sich in den Gerechtigkeitsbildern von Dieric Bouts, die er zwischen 1471 bis 1482 für das Rathaus von Löwen erschaffen hat, über die Bildgrenzen hinweg eine Handlung in unterschiedlichen Szenen [Abb. 1 u. 2]. Im Zentrum des ersten Bildes erkennt man eine Hinrichtung, im Zentrum des zweiten Bildes eine Feuerprobe, weitere Szenen spielen im Hintergrund. Diese Personengruppe, die die Geschehnisse kreisförmig umgibt, wurde innerhalb der kunsthistorischen Forschung heftig kritisiert. Das Argument bestand darin, daß die versammelten Figuren nicht an der Erzählung teilnehmen und dennoch prominent dargestellt wurden. Der Fragestellung des vorliegenden Sammelbandes folgend, kann diese abwertende Kritik an den Bildern jedoch positiv gewendet werden. Denn dadurch, daß die Narration ins Mittelfeld gerückt ist, entsteht nicht nur für die unbeteiligte Personengruppe, sondern auch für den Betrachter eine räumliche Distanz zù den szenisch erzählten Handlungen. In dem Moment aber, in dem der Betrachter gemeinsam mit weiteren Personen nahe vor dem Bild steht, schließt er den Kreis der versammelten Personen. Wie im Folgenden gezeigt werden soll, tritt der Betrachter dadurch in eine innerbildlich konstituierte Gemeinschaft ein. Diese 


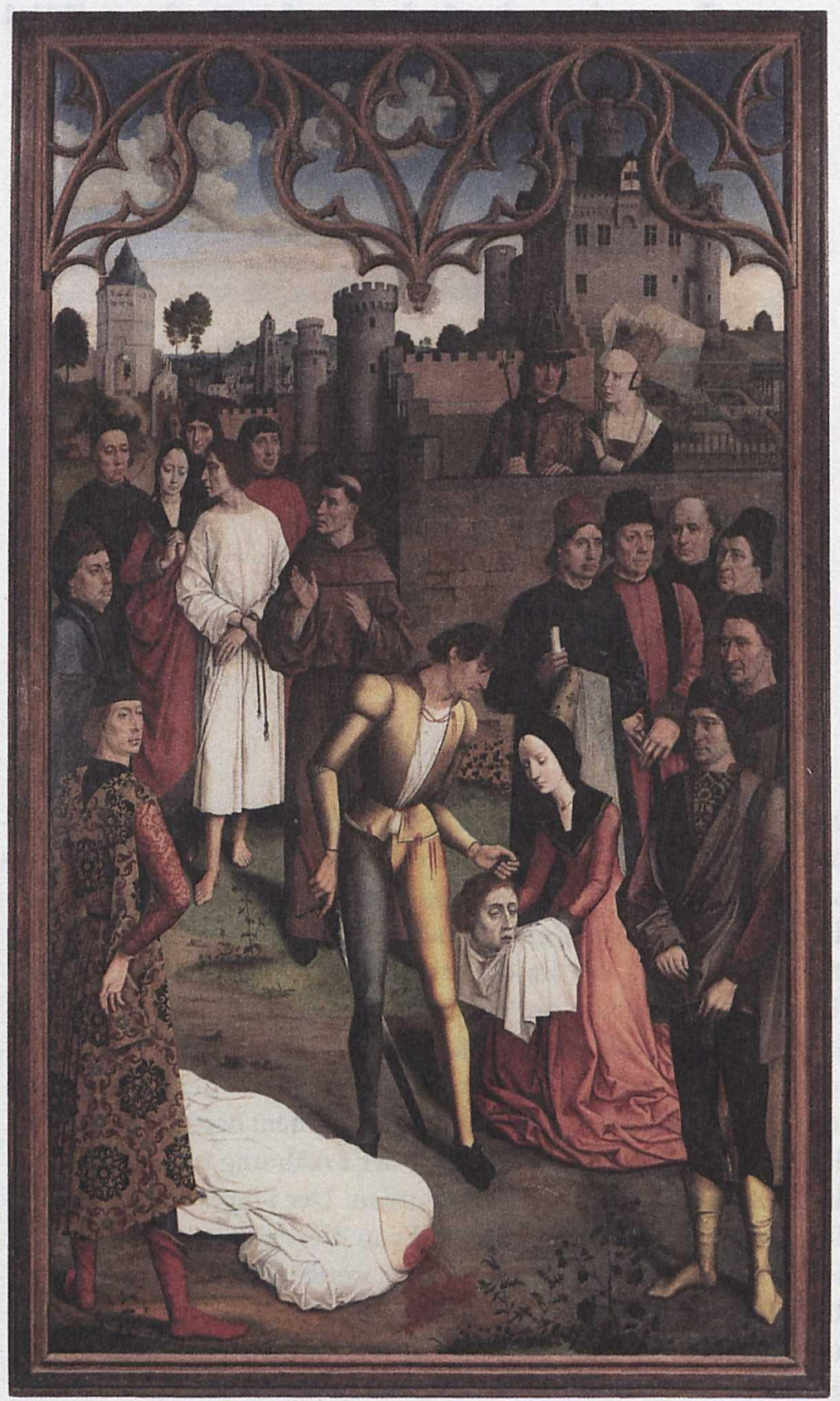

1 Dieric Bouts, Die Gerechtigkeit Ottos III., Die Hinrichtung des Unschuldigen (1473-1482).

Claudia Blümle 


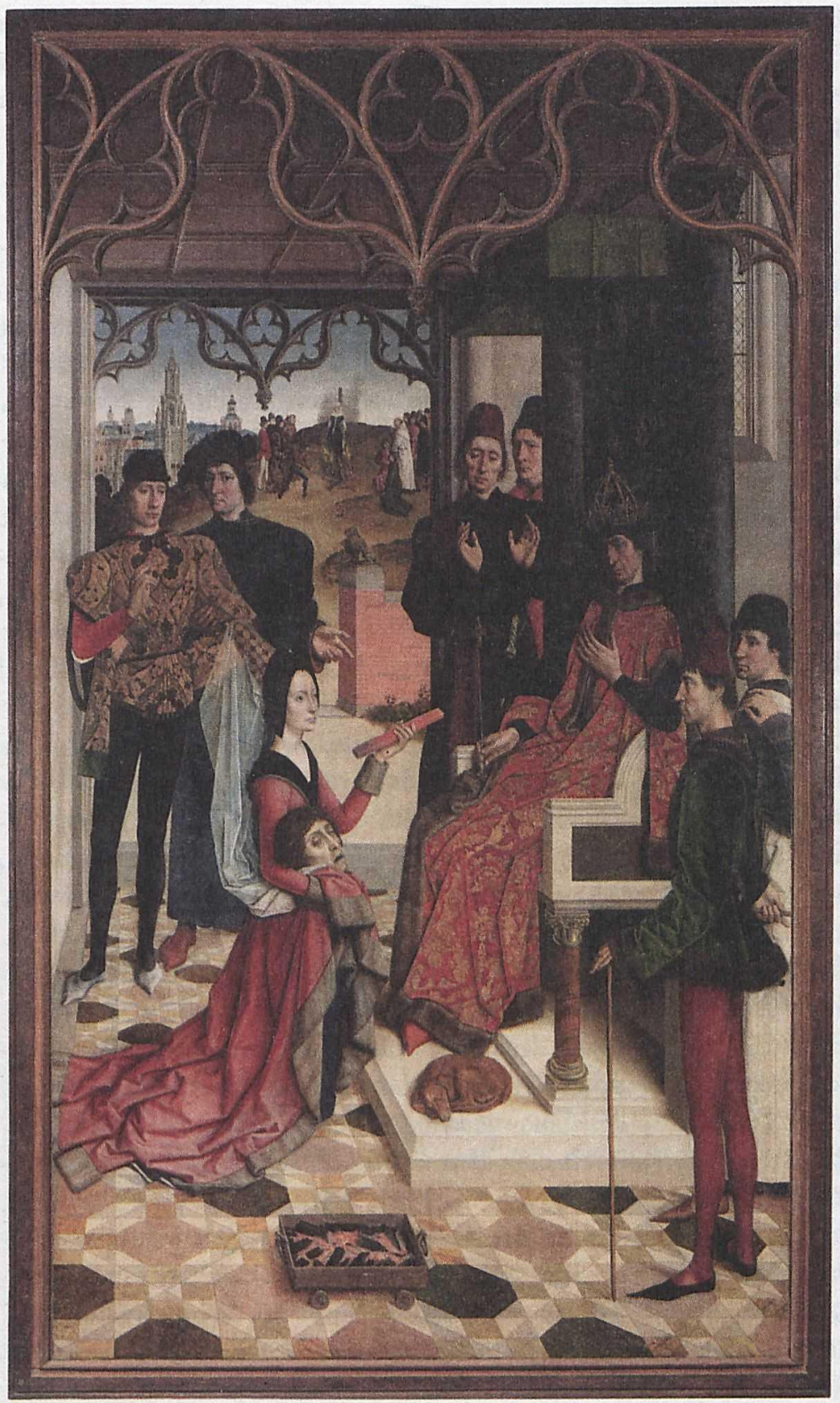

2 Dieric Bouts, Die Gerechtigkeit Ottos III., Die Feuerprobe (1471-1473). 
gemeinschaftsstiftende Anlage der Löwener Rathausgemälden von Bouts versetzt den Betrachter in die Position eines Schöffen, der nur im Kontext eines Gremiums und somit nur gemeinsam mit anderen Schöffen juridische Macht besaß.

\section{I}

Eine Chronik des 17. Jahrhunderts der Stadt Löwen vermerkt, daß am 20. Mai 1468 der Meister Dieric Bouts mit der Anfertigung von Bildern für das Rathaus beauftragt wurde. ${ }^{1}$ Zunächst sollte der Maler auf einer kleineren Tafel mit den Maßen $6 \times 6$ Fuß das Jüngste Gericht darstellen. Des weiteren erhielt der Maler den Auftrag für vier Bildtafeln im Umfang von $12 \times 26$ Fuß, zu denen die hier untersuchten Rathausbilder zählen [Abb.1 u.2]. Zusammen mit dem viel kleineren Jüngsten Gericht sollte der Maler insgesamt 500 Kronen erhalten. Aus den Abrechnungen der städtischen Rechnungsbücher, die über die einzelnen Arbeitsschritte Auskunft geben, geht hervor, daß der Löwener Theologe Jan van Haeght eigens für die Arbeit bezahlt wurde, die zu malende Erzählung auszusuchen. ${ }^{2}$ In den Akten von 1472 erhält er die Zahlungsbestätigung der Stadt Löwen für die Erfindung des Bildinhaltes und der Personen. ${ }^{3}$ Den Chroniken nach, die auf Gottfried von Viterbo oder auf Jacobus de Voragine zurückgehen, hatte die Gemahlin Ottos III.aus Rache falsche Anschuldigungen gegen einen seiner Grafen erhoben, weil er ihrer Verführungskunst widerstand. Der Kaiser ließ den unschuldigen Grafen ohne Verhör hinrichten. Dieser hatte jedoch zuvor die Gelegenheit ergriffen, die wahre Begebenheit seiner Gemahlin zu erzählen und sie darum zu bitten, nach seinem Tod seine Unschuld zu beweisen. Im ersten Gemälde sind in drei sich verschränkenden Etappen diese Episoden erzählend ins Bild überführt [Abb. 1]. Durch eine Mauer geschützt, wendet sich im Hintergrund des Bildes die Kaiserin, die den Grafen fälschlicherweise beschuldigt, ihrem Gemahl zu. Im Mittelfeld wird der unschuldige Graf, von seiner Frau begleitet, zur Hinrichtungsstätte geführt. Die dritte Etappe zeigt im vorderen Mittelfeld den enthaupteten Körper des Grafen, während der Henker dessen Haupt der Witwe reicht. Auf dem rechten, zweiten Bildteil wird die vor Kaiser Otto III.kniende Gräfin im Moment der Feuerprobe dargestellt [Abb.2]. Während sie mit dem rechten Arm das Haupt ihres Gemahls umfasst, hält sie in der linken Hand das glühende Eisen, um seine Unschuld zu beweisen. Indem die Gräfin sich der Feuerprobe unterwirft und diese besteht, muß sich der König der Anklage stellen und sein Fehlurteil 
erkennen. Daraufhin läßt er auch seine eigene Gemahlin auf dem Scheiterhaufen verbrennen, wie im Hintergrund, im Durchblick durch die gerahmte Öffnung, zu sehen ist. ${ }^{4}$ Aus diesem Grund wurde später dem linken Gemälde der Titel Die Hinrichtung des Unschuldigen [Abb. 1] und dem rechten Gemälde der Titel Die Feuerprobe [Abb.2] gegeben.

Die Forschung ist sich einig, daß diese beiden Rathausgemälde als frühe Profanmalerei ein noch nie dargestelltes Thema entwickeln, das nur im Rekurs auf schon vorhandene Bildtypen überhaupt für die Betrachter lesbar gemacht werden konnte. Deshalb mußte Bouts nicht nur auf die schriftlichen Quellen von Gottfried von Viterbo und Jacobus de Voragine, sondern auch auf ein konventionelles Bildvokabular mit anderem Bildinhalt zurückgreifen, damit der Betrachter die dargestellte Geschichte von sich aus und ohne externe schriftliche Hilfe erkennen konnte. ${ }^{5} 1902$ hat Paul Heiland die Hinrichtung des unschuldigen Grafen mit der Enthauptung Johannes des Täufers verglichen, die Rogier van der Weyden von 1446 bis 1453 auf dem linken Flügel des Johannesaltars dargestellt hatte [Abb.3]. ${ }^{6}$ Zwischen dem linken Bild von Bouts und der viel kleineren Enthauptungsszene können unmittelbare Parallelen gezogen werden, was einerseits die Erzählform und andererseits die Figur des Henkers mit den grüngelben Strumpfbeinen betrifft. ${ }^{7}$ Die jüngste Forschung nimmt weniger die visuelle Gliederung der Erzählform und die Körperhaltung des Henkers auf, sondern geht mehr einer ikonographischen Lektüre nach. Sie weist darauf hin, daß Bouts die Hinrichtung so darstellen würde, als handle es sich um die Enthauptung Johannes des Täufers. Nach Didier Martens hat das im 15. Jahrhundert verbreitete Bild als Modell für die Hinrichtung des Unschuldigen gedient. Denn wenn die Legende von Otto III. keine eigene ikonographische Tradition besaß, dann kann angenommen werden, daß sich der Maler auf diejenige bezog, die zu seiner Zeit auf einem analogen Bildinhalt aufbaute. Das tertium comparationis der beiden Bilder bestehe darin, daß es sich in beiden Texten um den Tod eines Unschuldigen durch Enthauptung handelt.

Eine zweite Darstellung mit einer Enthauptung des Johannes von Hans Memling auf der linken Tafel des Triptychons der Mystischen Vermählung der heiligen Katharina kann zum Vergleich herangezogen werden, da sich dieses Bild wiederum auf Bouts bezieht [Abb. 5]. Das auf das Jahr 1479 datierte Gemälde nimmt die Bildstruktur von Bouts auf, die Martens wie folgt beschreibt: 
»Die beiden Repräsentationen, diejenige von Bouts und diejenige von Memling, bringen auf der ersten Ebene die gleichen Personen ins Werk: Der Henker mit seinem Schwert nimmt in einer engen Bekleidung eine zentrale Position ein; zu seinen Füßen liegt schiefwinklig der leblose Körper eines Hingerichteten; rechts, ein wenig abseits, nimmt eine Frau aus den Händen des Henkers den Kopf des Verurteilten-es handelt sich um Salome bei Memling und um die stolze Gräfin bei Bouts. Einige Zeugen assistieren stehend zur Szene. $\aleph^{8}$

Die Frage, inwiefern sich inhaltlich die Darstellung der Enthauptung des unschuldigen Grafen von einer Darstellung des Johannes des Täufers unterscheidet, und in welcher Weise dies zu interpretieren ist, beantwortet Martens dahingehend, daß die Übernahme eines figurativen Schemas nicht nur zum Verständnis der repräsentierten unbekannten Episode führe, sondern diese auch erhöhe. Ikonographisch führt die Assoziation mit Johannes dem Täufer in Bezug auf das Bild von Bouts zu einer Aufwertung der Gräfin, die ausgehend von dem Typus einer christlichen Märtyrerin in eine obskure Figur aus der mittelalterlichen Literatur transformiert wurde. ${ }^{9}$ Zusätzlich nimmt die Gräfin eine andere Körperhaltung als Salome ein. Einerseits wird sie nicht stehend, sondern in beiden Bildern kniend dargestellt. In dieser Haltung nimmt sie im linken Bild mit einem weißen Tuch den abgetrennten Kopf entgegen, weshalb diese Geste mit derjenigen der heiligen Veronika verglichen wurde ${ }^{10}$, und im rechten Gemälde hält sie den Kopf des Enthaupteten wie ein Martyriums-Attribut im Arm. ${ }^{11}$ Die kniende Haltung, die die Gräfin am deutlichsten von einer Salome unterscheidet, erinnert schließlich auch an Stifterporträts.

Die Bildvergleiche mit den Johannestafeln van der Weydens und Memlings erweisen sich jedoch besonders in Bezug auf die theatrale Anordnung der Figuren im Bildraum als aufschlußreich, da in allen drei Bildern ein verschränkendes Verhältnis zwischen Architektur und Landschaft konstruiert wurde. Bei van der Weyden findet die Enthauptung vor einem gotischen, mit Skulpturen versehenen Portal statt, das die Einsicht in einen langen Flur mit Treppen und an dessen Ende in einen Festsaal eröffnet, der mit dem Doppelbogenfenster mit Lünette wiederum einen Ausblick auf die Landschaft ermöglicht. Auf der rechten Seite des Bildes befindet sich eine weitere fensterbogenförmige Öffnung, die ein rotes Stadttor in 
der Landschaft und eine Stadtmauer zeigt. Bouts kehrt die Verhältnisse zwischen Architektur und Landschaft um, indem bei ihm die Stadtmauer eine Grenze zwischen Innen und Außen markiert. Das Königspaar befindet sich innerhalb des Schloßgartens, während die Hinrichtungsszene außerhalb, vor den Stadttoren, stattfindet. Der Verlauf der Mauer eröffnet eine Tiefe, die auf einen Stadtturm mit offenem Tor zuläuft. Mit der in die Weite verlaufenden Stadtansicht und der sich vom Grasgrün ins Blaugrau verfärbenden Hügellandschaft im Hintergrund entsteht eine Ferne, in die gleichzeitig ein weiter Horizont eingeführt wird. Memling verschränkt schließlich diese beiden Architektur- und Landschaftskonzepte. Einerseits findet die im Vordergrund sich abspielende Enthauptungsszene im Freien statt, so daß die Landschaft mittels der Stadtmauer eine Tiefe erhält, die von dem nach rechts geschwungenen Gewässerverlauf aufgenommen wird. Andererseits eröffnet die Rundbogenöffnung einen Einblick in den Festsaal mit der vor Herodes tanzenden Salome.

Eine weitere entscheidende Veränderung bei Bouts betrifft die Figur des Henkers, der in den beiden Johannestafeln auf der vordersten Bildebene zu finden ist [Abb. 3 u. 5], während er in den Rathausgemälden von Bouts räumlich in klarer Weise ins mittlere Feld gerückt wurde [Abb.4]. Der Schatten der vorderen rechten Figur und die relativ hohe Pflanze, die fast bis zum Faltenwurf des roten Gewandes der Gräfin reicht, markiert die räumliche Tiefe der Szene mit der Überreichung des enthaupteten Kopfes des Grafen. Der Henker, der in den beiden Johannesbildern als Rückenfigur dargestellt ist, wird in dem Bild von Bouts innerhalb des mittleren Feldes mit verdrehtem Körper und von vorne dargestellt. Das Schwert, das sich mit dem dunkelgrünen Bein überkreuzt, sowie die parallel verlaufende Fußstellung betonen die Frontalansicht des Unterkörpers, die in eine Drehung des Oberkörpers übergeht und in dem klar ins Profil gewendeten Kopf des Henkers mündet. Im Gemälde van der Weydens stehen Salome und der Henker sehr nahe beieinander, während ihre Köpfe in entgegengesetzte Richtungen gedreht sind, so daß sie sich auf diese Weise nicht anblicken müssen. Bei Bouts hingegen wird eine in sich geschlossene kreisförmige Einheit zwịschen Henker und Gräfin entwickelt, wodurch gerade mittels der Vorderansicht des Henkers der Eindruck einer offensichtlichen Schauansicht der Hinrichtungsszene entsteht. Aufgrund der vorgenommenen Änderungen von Bouts entsteht in den Rathausbildern eine räumliche Distanz zur Hinrichtungsszene, die nicht zuletzt durch die umstehenden Personen hervorgehoben wird. 


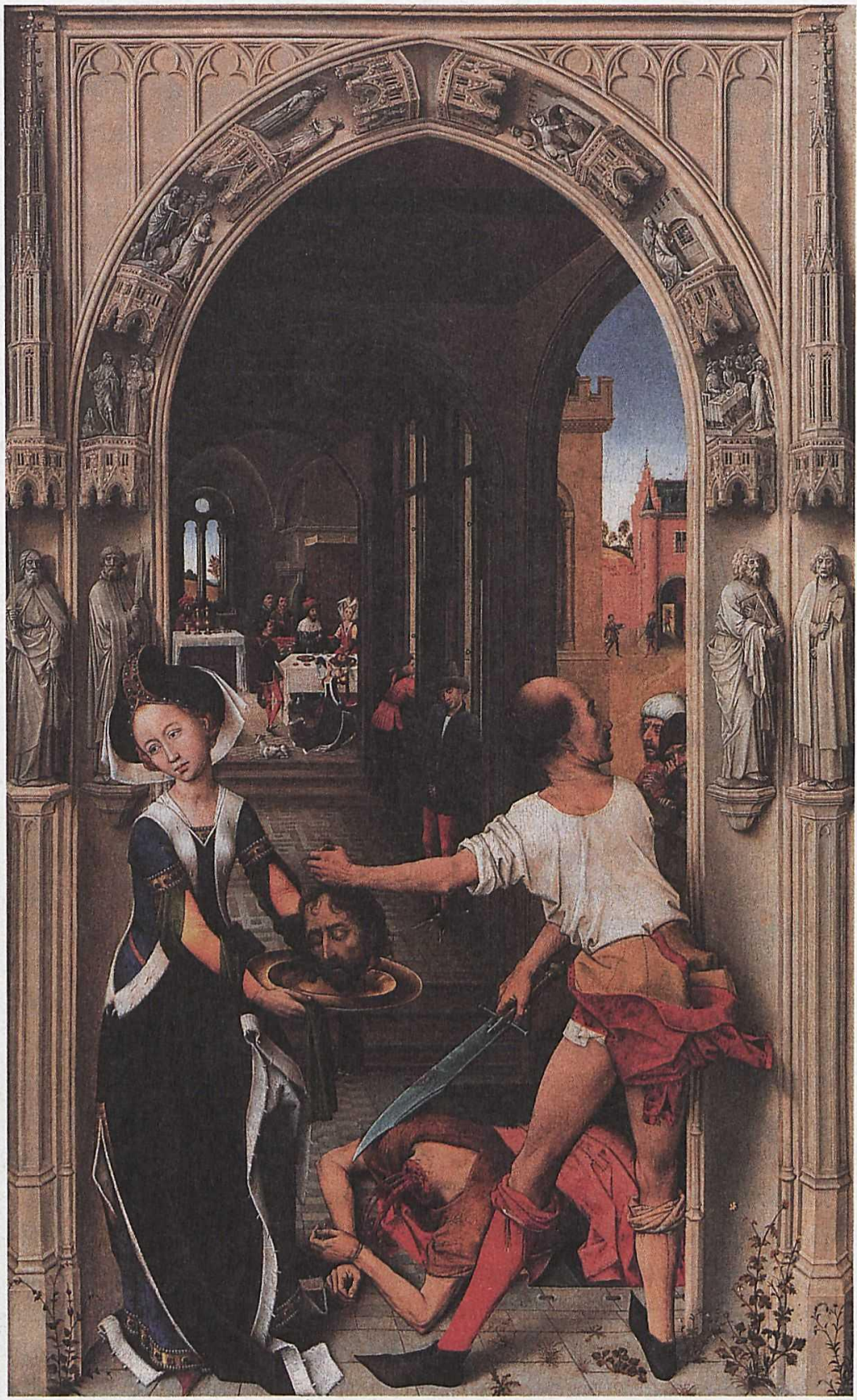

\section{Rogier van}

der Weyden, Die

Enthauptung Jo-

hannes des Täufers

(um 1446-1453).

Claudia Blümle 


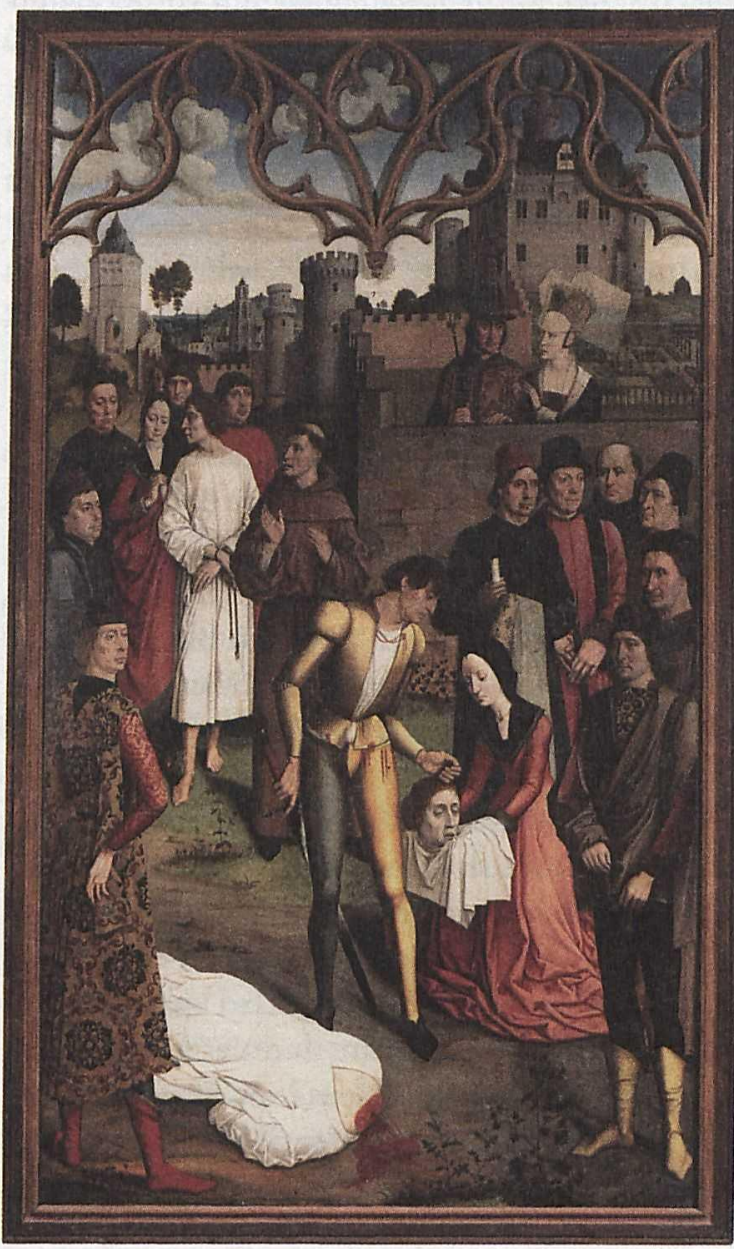

4 Dieric Bouts, Die Gerechtigkeit Ottos III., Die Hinrichtung des Unschuldigen (1473-1482).

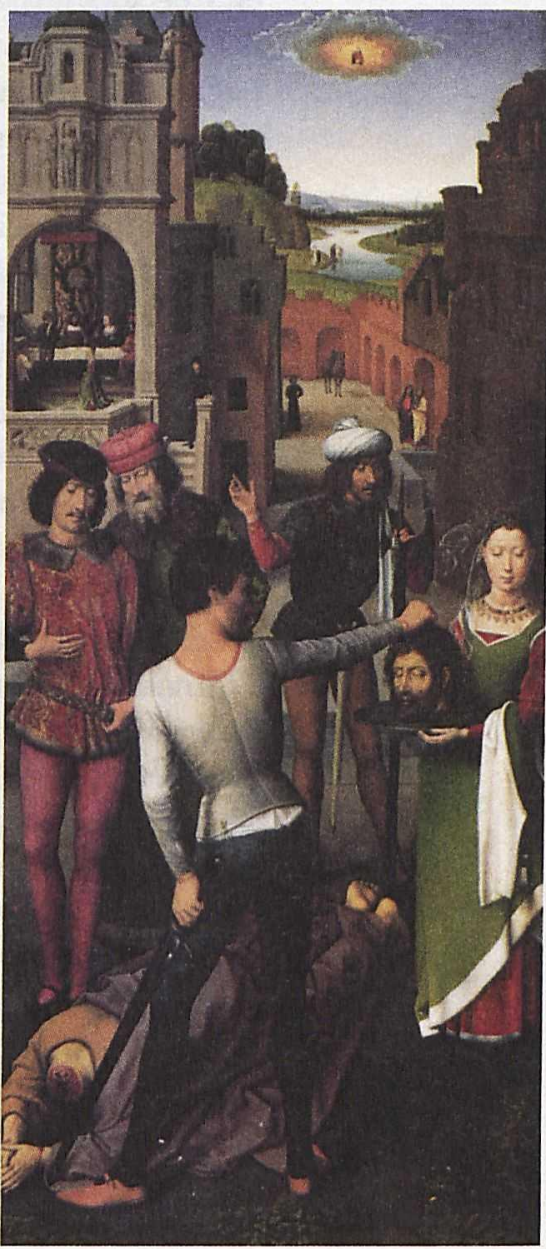

5 Hans Memling, Die Enthauptung Johannes des Täufers (um 1479). 
In der Johannesdarstellung van der Weydens sind ebenfalls beobachtende Figuren in die Szenerie eingefügt. Eine männliche Person blickt, sich aus dem Fenster lehnend, auf den sich nach rechts hin öffnenden Platz, während etwas weiter vorne eine Figur dem Fenster den Rücken kehrt und auf den Boden schaut. Noch näher am eigentlichen Geschehen lugen hinter der Maueröffnung rechts zwei weitere Personen hervor, wobei die vordere mit einem Monokel auf den enthaupteten Körper des Johannes blickt, der in dem Schlund der Kerkertreppe zu verschwinden scheint. Die beiden beobachtenden Personen in den Löwener Rathausgemälden im Vordergrund nehmen hingegen genau diejenigen Plätze ein, die in den beiden Johannesdarstellungen den Protagonisten der Erzählung vorbehalten sind. Anstelle von Salome, Johannes dem Täufer und dessen Henker befinden sich auf der vordersten Bildebene der Rathausgemälden von Bouts zwei sich gegenüberstehende Figuren, die spiegelverkehrt am Rande des Bildes, links und rechts, die Hinrichtungsszene rahmen. Besonders auffällig ist dabei, daß der Patrizier links die Funktion der Rückenfigur und ebenso die Beinhaltung vom Henker der anderen Tafeln übernommen hat. In einem spitzen Stiefel, dessen roter Strumpf ebenfalls am oberen Rand in Falten heruntergezogen ist, verläuft der rechte Fuß nahe und parallel zum Bildrand. Der Träger des edlen Gewandes aus Golddamast am linken Bildrand wird insofern in derselben Körperdrehung wie der Henker gezeigt, als seine Kopfhaltung in Dreiviertelansicht und sein Blick aus dem Bildraum hinaus anders ausgerichtet sind als sein Oberkörper. Als trompe-l'ceil scheint der spitze Ellenbogen, der in die gleiche Richtung wie die Blickführung weist, in den Betrachterraum vorzustoBen. Dieser aufgestützte rechte Arm, der durch die Drehung des Unterarms die innere Handfläche sichtbar werden läßt, entspricht genau der Armhaltung von Memlings Henker, der sein Schwert zur Enthauptung auf die gleiche Weise in der Hand hält. Die Gegenüberstellung von einer frontal ausgerichteten Figur zu einer Rückenfigur, wie sie für die Darstellung der Salome und des Henkers bei van der Weyden angewandt wird, wird bei Bouts von zwei Personen übernommen, die nicht in die Erzählung integriert sind, sondern diese statt dessen rahmen.

Der Vergleich mit der Enthauptung Johannes des Täufers macht deutlich, daß die Menschenansammlung um die Szene herum, die bei van der Weyden einen externen Beobachtungsort im Hintergrund einnimmt, bei Bouts gerade umgekehrt prominent in den Vordergrund gerückt ist. An vorderster Stelle haben diese 
Personen die Körperhaltungen und Plätze der repräsentativen Protagonisten aus der Bibel eingenommen. Die Schaulustigen bei den Johannesdarstellungen, die bei van der Weyden durch die Bauwerke und bei Memling durch andere Figuren halbverdeckt auf die Szenen blicken, beginnen in dem Rathausbild von Bouts eine Hauptrolle zu spielen, ohne daß sie in der Erzählung irgendeine Rolle oder Funktion einnehmen. Mit der Verschiebung und Umbesetzung der Bildformeln instrumentalisiert Bouts die Plätze sowie die Funktionen des Henkers und der betrachtenden Volksmenge, um diese statt dessen durch individuell hervorgehobene Figuren zu ersetzen, die sich indifferent zum Geschehen verhalten.

In gleicher Weise umrahmen verschiedene Figuren die Szene der Feuerprobe [Abb.6]. Der mehrmals herangezogene Vergleich mit Dedikationsbildern ${ }^{12}$, wie die Präsentation eines Manuskriptes für Philipp den Guten von Girart de Roussillon [Abb.7], läßt hinsichtlich der Raumgestaltung und Versammlung unterschiedlicher Personen einige Ähnlichkeiten mit der Feuerprobe erkennen. Die zentralperspektivische Konstruktion eines Innenraumes mit einer Türöffnung im Hintergrund und die seitliche Ansicht eines mit Goldbrokat geschmückten Baldachinthrones bei Bouts weisen starke Ähnlichkeiten mit dem Dedikationsbild Roussillons auf. Wie in zeitgenössischen illustrierten Manuskripten weit verbreitet, zeigt dieses Bild einen Autor, der sein vollbrachtes Werk seinem Auftraggeber und Herrscher überreicht. Der Autor kniet demütig mit dem Buch in der Hand, während der Herrscher, auf einem erhöhten Thron mit Baldachin, von seinen aufrecht stehenden Beratern umgeben ist. An die Stelle des Autors, der dem Herrscher das ihm gewidmete Buch überreicht, tritt in den Rathausgemälden von Bouts die ebenfalls kniende Gräfin, die einen glühenden Feuerbalken in der Hand hält, um mittels der Feuerprobe den König anzuklagen. Bei der Feuerprobe konnte Bouts daher ebenso wie bei der ersten Tafel des Diptychons auf eine bekannte, wiewohl nicht christliche, sondern höfische Ikonographie zurückgreifen. Aus diesem inhaltlich maßgeblichen Unterschied entwickelt Martens eine Ähnlichkeit, um aus der Feuerprobe eine reine Angelegenheit des Hofes zu machen.

»Auch wenn es keine fundamentale Ähnlichkeit zwischen der Figur der Gräfin, die gekommen ist, um die Unschuld ihres Gemahls zu beweisen, und dem Autor, der sein Werk überreicht, so sind sie dennoch durch den Parallelismus der Situation vereint: alleine, angesichts des Hofes, warten sie auf das Urteil eines Souveräns. " $^{13}$ 


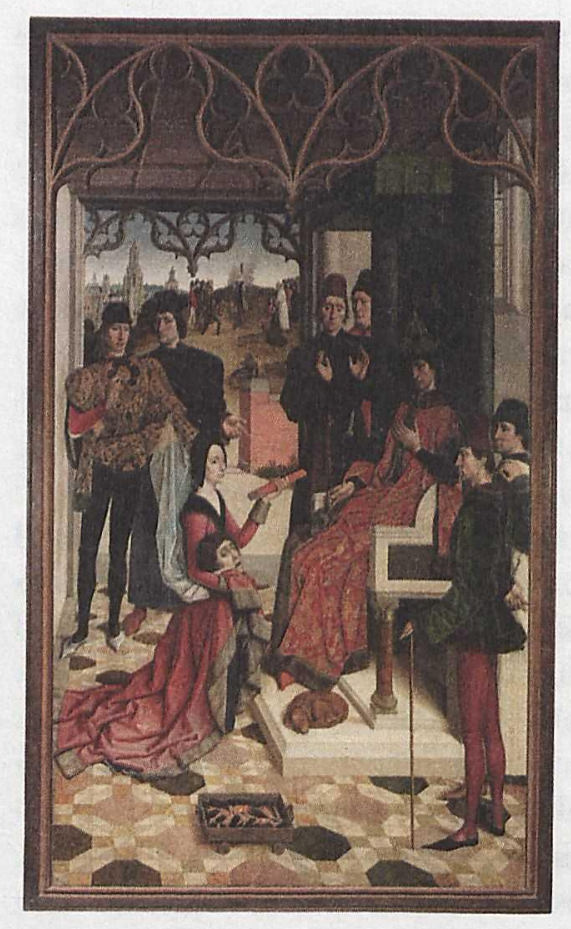

6 Dieric Bouts, Die Gerechtigkeit Ottos III., Die Feuerprobe (1471-1473).
Doch stellt sich hier wie beim Vergleich mit den Johannesdarstellungen nicht nur die Frage, inwiefern Bouts die Bildformen anderer bekannter Ikonographien aufgenommen hat, sondern ebenso, in welchem Maße er sie verändert und ihnen dadurch eine andere Bedeutung gegeben hat. Zunächst wird in der Feuerprobe nicht der Einblick in einen schmalen langen Korridor, sondern der Ausblick auf eine Terrasse und eine Stadt eröffnet, um mit der Hinrichtungsszene auf dem Hügel den Fortgang der Geschichte zu erzählen. So kombiniert Bouts die Dedikation von Roussillon mit der Raumstruktur und der Erzählung der Johannestafel von Rogier dadurch, daß am Ende des Korridors ein Einblick in den Festsaal mit der tanzenden Salome möglich ist. Der gemeinsame Vergleich der höfischen mit der christlichen Darstellung zeigt, wie Bouts den Innenflur in eine Terrasse verwandelt, und so die Hinrichtungsszene mit der verbrennenden Kaiserin im Freien stattfinden läßt.

In der Feuerprobe führt Bouts des weiteren die genau gleichen Änderungen wie bei der Hinrichtung des Unschuldigen durch, indem die Handlung des Gottesurteils ins Mittelfeld des Bildraumes gesetzt ist und von verschiedenen Personen umkreist wird. Die Handlung in der Dedikation von Roussillon findet statt dessen 


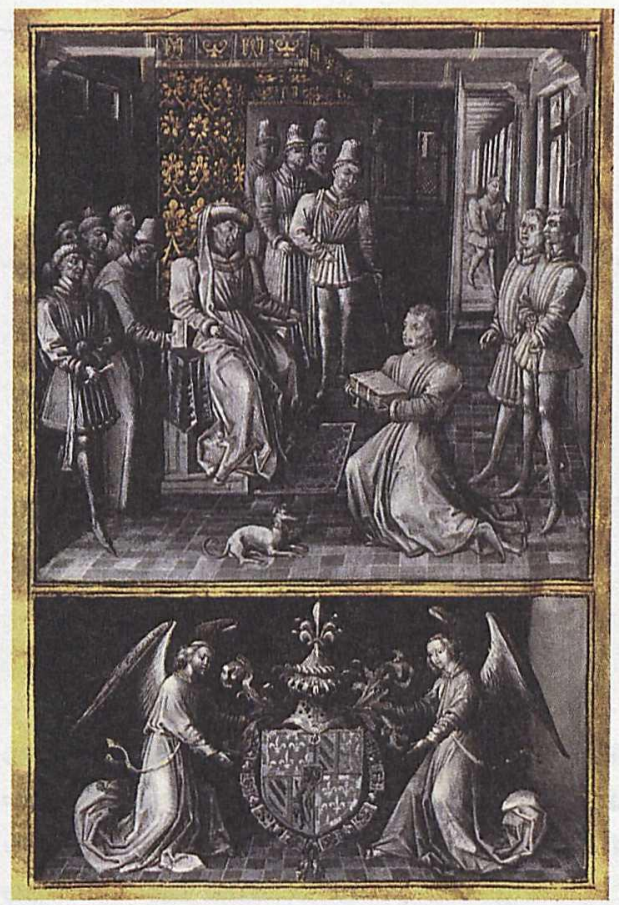

auf der vordersten Bildebene statt, ähnlich wie bei den Johannesdarstellungen von Memling oder van der Weydens. Während der kniende Autor gemeinsam mit dem Hund und dem Höfling auf der vorderen Bildebene eine Linie bildet, rückt die Gräfin mit dem Feuerbalken deutlich in den Hintergrund, und auch der Hund, der zusammengerollt zu den Füßen des Königs schläft, wird nach hinten geschoben. An die Stelle des Hundes tritt der Feuerkasten mit der glühenden Kohle, so daß im Vergleich mit der Miniaturdarstellung einzig jene Figur, die sich auf einen langen Stab stützt, ihren Platz auf der vordersten Bildebene beibehält. Im Gegensatz zur Darstellung Philipp des Guten, der sich zum Autor hinwendet, bildet Kaiser Otto III.zusammen mit der knienden Gräfin keine diagonale, sondern eine horizontale Linie im mittleren Bildraum.

Diese Bildvergleiche zeigen, daß sich die Figurenanordnung bei Bouts in mehrfacher Hinsicht deutlich von ihren ikonographischen Vorbildern unterscheidet. Einerseits befinden sich die Figuren der ikonographisch relevanten Szenen aus der Hinrichtung des Unschuldigen und der Feuerprobe nicht auf der vordersten Bildebene, während sowohl die Salome und der Henker in Die Enthauptung Johannes des Täufers als auch der Autor in der Dedikationsminiatur

7 Meister Girart de Roussillon, Dedikation eines Manuskriptes für Philipp den Guten (1462). 
von Roussillon ihre Plätze im Raum an vorderster Stelle einnehmen. Anderseits rücken statt dessen die aufgrund ihrer zurückhaltenden Gesten und ihres unbeteiligten Gesichtsausdrucks in der Forschung so oft kritisierten männlichen Figuren prominent in den Vordergrund. Indem die linke Person als Rückenfigur und die rechte Person in Vorderansicht dargestellt ist, stehen sich beide auf der vorderster Bildebene gegenüber. Das Gleiche gilt für die beiden männlichen Figuren in der Feuerprobe, die rechts im Bild auf der Höhe des Feuerkastens situiert sind. So ist deutlich, daß die Erzählung aus der Legende Ottos III. nicht wie üblich auf der vordersten Bildebene stattfindet, sondern daß die Handlungsmomente, die den Exempla entnommen wurden, szenisch ins Mittelfeld gerückt sind und wie im Theater von verschiedenen unbeteiligten Zuschauern umrahmt werden.

\section{III}

Im folgenden soll gezeigt werden, daß die Rathausgemälde von Bouts nicht für einen einzelnen Betrachter, sondern für mehrere Betrachter konzipiert sind, die gleichzeitig dem Bild gegenüber stehen. Dies kann zunächst anhand des Experimentes, das Cusanus für die Brüder am Tegernsee entwickelt hat, bestätigt werden. Cusanus schickte zusammen mit seiner Schrift Über das Bild (De icona), bekannter unter dem Titel De visione Dei ${ }^{14}$, eine Vera Ikon nach Brixen, um sein theologisches Verständnis zu exemplifizieren. In der Abhandlung beschreibt er, daß der Betrachter vor dem mitgeschickten Bild von jedem beliebigen Standpunkt aus vom dargestellten Christus 


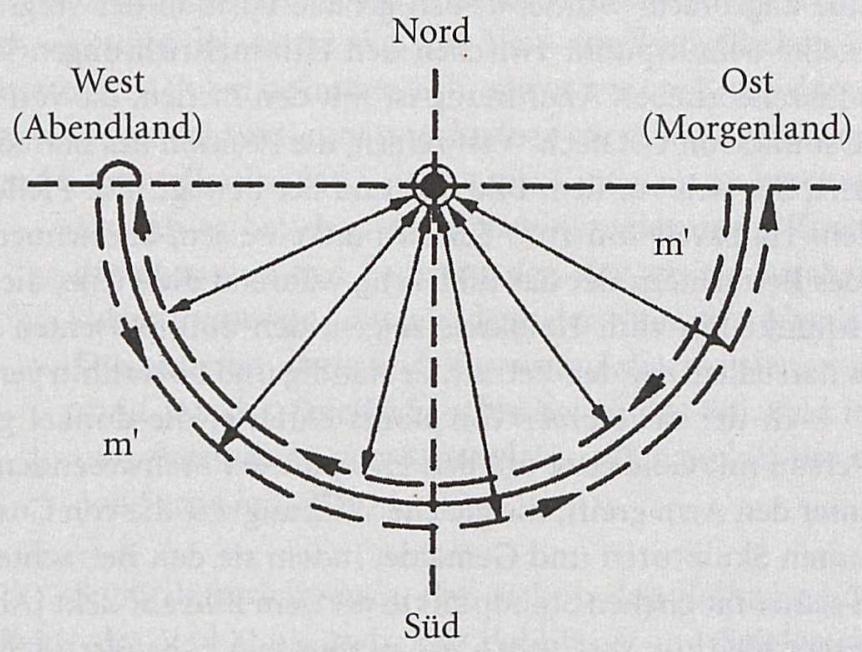

angeblickt werde. Eben diesen Blick, der den Betrachter in seiner Bewegung vor dem Bild verfolgt, konnte Cusanus an mehreren Kunstwerken feststellen, zu denen auch das Brüsseler Rathausgemälde van der Weydens zählt. Die zentrale Aussage von Cusanus, daß anhand dieses Bildes die paradoxe Figur der coincidentia oppositorum sinnlich wahrnehmbar wird, gelingt nach Michel de Certeau jedoch nur innerhalb einer Gemeinschaft, die in diesem Fall eine klerikale Bruderschaft ist. ${ }^{15}$ Visuell manifestiert sich die Figur der coincidentia oppositorum in der Idee, daß der Blick Gottes partikular und zugleich allgegenwärtig ist. Das bedeutet, daß jeder einzelne Bruder vor dem Bild in singulärer Weise von Gott angeblickt wird. Doch wenn er dies einem anderen Bruder mitteilt, behauptet dieser, daß er ebenfalls von Gott angeschaut werde, was über den Verstand hinausgehe und als unmöglich erscheine. Erst wenn die Brüder gemeinsam vor dem Bild stünden, könnten sie sich gegenseitig bezeugen, daß sie je einzeln und zugleich alle gemeinsam von Gott angeblickt werden. Erst in der gemeinsamen und mitgeteilten Zeugenschaft des Erlebten sei der Glaube an Gott und seine mystisch entwickelte Theologie erfaßbar. Das Zusammenfallen von Gegensätzen, das mit dem Verstand nicht nachvollzogen. werden kann, veranschaulicht den absoluten Ort der göttlichen Wahrheit, welche vom Menschen niemals erreicht werden könne. Die notwendige Bewegung der Personen vor dem Bild, die niemals nur ein Dargestelltes sehen, sondern ihrerseits erblickt werden, ist in einem Schema von de Certeau verdeutlicht [Abb.8]. Im Grundriß steht die horizontale Linie für die Wand, an der das 
Gemälde angebracht wurde, dessen genaue Position der vergrößert dargestellte Schnittpunkt zwischen den Himmelsrichtungen ist. In der halbkreisförmigen Anordnung ist mit den Pfeilen, die von West nach Ost und von Ost nach West zeigen, die Position des Betrachters markiert, der sich vor dem Bild hin und her bewegt. Die Pfeile, die von dem Halbkreis hin zum Schnittpunkt weisen, bezeichnen das Auge des Betrachters, der das Bild sieht, während die Pfeile, die vom Schnittpunkt hin zum Halbkreis zeigen, den omnipräsenten Blick Gottes darstellen, der den Betrachter ständig und überallhin verfolgt.

In der Feuerprobe von Bouts entfaltet die dunkel gekleidete Person mit Goldkette um den Hals, die dem schwörenden Zeugen unter den Arm greift, die gleiche Wirkung wie die von Cusanus erwähnten Skulpturen und Gemälde, indem sie den Betrachter auf jedem seiner möglichen Standpunkte vor dem Bild anblickt [Abb.2]. Im Unterschied zur Vera Ikon, die Cusanus seinen Brüdern schickte, handelt es sich bei Bouts jedoch nicht um den Blick Christi, sondern um den Blick eines städtischen Zunftmitgliedes. Dabei ist insbesondere von Interesse, daß es sich wie bei der klerikalen Bruderschaft in Brixen um eine Gemeinschaft handelt, jedoch um die juridische Urteilsinstanz der Schöffen. In der Art, wie sich die Betrachter in einer Gemeinschaft vor dem Bild bewegen können, verhalten sie sich des weiteren wie ein Theaterpublikum, das einer Aufführung auf einer Simultanbühne beiwohnt. Indem die männlichen Figuren in den Rathausbildern von Bouts verschiedenen Szenen einer kontinuierlichen Erzählung gegenüberstehen, entsprechen sie dem Theaterpublikum der Passions-, Mysterien- und Mirakelspiele, wie es in der Theatergeschichte Kindermanns beschrieben wird:

»Die mittelalterliche Bühne wurde von einer Fülle uneinheitlich nebeneinander gestellter Örtlichkeiten gebildet, an denen zu gleicher Zeit und nacheinander das Spiel sich abwickelte. Das Auge des Zuschauers konnte nur hin- und hergehend dem simultanen Ablauf der Handlung folgen. ${ }^{16}$

Die Szenenverknüpfung war ein dramaturgisches Problem, denn das Warum der Aufeinanderfolge mußte plausibel gemacht werden. Aus diesem Grund trat oft ein praecursor oder Theaterherold hervor und erklärte den Zusammenhang der Szenenabfolge oder untermauerte ihn durch Exempel aus dem Alltagsleben. ${ }^{17}$ Bisweilen wurde bei einem Szenenwechsel die Zuschauermenge aufgefordert, still $\mathrm{zu}$ werden, und die Ruhestörer im Publikum wurden halb scherzhaft von einem Teufel abgeschleppt und vor aller Augen in die 
Hölle geworfen. Das Publikum, das auch ermuntert wurde, in die Szenen einzugreifen, setzte sich aus allen gesellschaftlichen Schichten zusammen. Dabei befand es sich, genau wie bei Bouts dargestellt, größtenteils auf engem Raum unmittelbar vor den aufgeführten Szenen und betrat teilweise den Spielort, wie Kindermann beschreibt:

»Da gab es bei den Marktplatzinszenierungen Zuschauer, die oben von den Fenstern der Häuser aus zusahen: Sie sahen immer nur das gerade in der Nähe sich Abspielende. Die anderen aber, und das waren die meisten, standen rund um das Spielfeld, ja bis tief in das Spielfeld hinein, und zogen dann von Schauplatz zu Schauplatz der einzelnen Szene mit. ${ }^{18}$

Somit läßt sich sagen, daß sich in den Rathausgemälden von Bouts das Verhältnis zwischen Publikum und Spielgeschehen auf ganz ähnliche Weise darbietet wie auf einer spätmittelalterlichen Simultanbühne. Folgt der Betrachter den einzelnen Szenen in ihrer Reihenfolge, so lassen sich diese wie in anderen Simultanbildern etappenweise abschreiten. Des weiteren ist die kreisförmige Anordnung des Publikums bei Bouts zentral, die auch über die Bildgrenzen hinweg funktioniert. Dies entspricht theaterhistorisch am ehesten der in den Niederlanden besonders häufigen Form eines "profanen Simultan-Theater[s] großen Stils«, den sogenannten Moralitäten. ${ }^{19}$ Die Anordnung des Publikums, das bei den Moralitäten sowohl sitzend als auch stehend zusah, verweist auf ein antikes Verständnis des Theaters. Als Quellen dienten hier, Max Herrmann zufolge, Holzschnittillustrationen sowie Miniaturen, die Elemente und Darstellungen eines Theatrum Romanum aus dem 14. und 15. Jahrhundert zeigen. ${ }^{20}$ Ein Plan von 1440 sowie eine Rekonstruktion für das englische Moralitätenspiel Schloß der Beharrlichkeit zeigen, wie eine entsprechende Bühne von einem Publikum in kreisförmiger Anordnung umgeben ist. Dies entsprach jedoch einem antiken, szenischen Verständnis von Bühne und Betrachter, dessen Wiederentdeckung in den Niederlanden den Rhetorikkammern zu verdanken ist. Am Ende des Mittelalters wurden in vielen niederländischen Städten Kamers van Rethorica gegründet, die aus geistlichen Bruderschaften hervorgegangen waren und deren Mitglieder Rederijkers ${ }^{21}$ hießen. Zur 1401 in Brüssel gegründeten Rhetorikkammer Het Boek gehörte auch der Herzog Johann von Brabant, der Stifter der Universität Löwen. ${ }^{22}$ Zusammen mit den Lukas-Gilden, den Malerzünften, konzipierten und veranstalteten die Rederijkers in den Niederlanden diese theatralen Spiele, die die Form 
von Wettbewerben annahmen. Für die Jahre 1431-1620 sind 65 offizielle Rederijker-Wettkämpfe (Landjuweelen) nachgewiesen, die teilweise bis zu zehn Monate Vorbereitungszeit in Anspruch nahmen. ${ }^{23}$ Im Gegensatz zu Italien und Frankreich, wo gewöhnlich eher scharfe Gegensätze zwischen mittelalterlichen und neuzeitlichen Theaterformen bestanden, findet man bei den Rederijkers einen langsamen und übergreifenden Übergang der spätmittelalterlichen Spiel- zu renaissancemäßigen Bühnenformen. ${ }^{24}$ Als antike Stoffe noch nicht auf der Bühne inszeniert wurden, übernahmen die Rederijkers jedoch bereits Formen des antiken Theaters, was zu einer langsam fortschreitenden Neukonstellation des räumlichen und performativen Verhältnisses von Bühne und Theaterpublikum führte.

Die Horizontlinie und die in Lebensgröße gemalten stehenden Figuren bei Bouts weisen darauf hin, daß der Augpunkt und die Maßeinheiten der gesamten Bildanlage in ein Wirklichkeitsverhältnis von 1:1 zu setzen sind, wie die Darstellung des Feuerkastens betont. Der Blick von oben auf den am Boden liegenden Feuerkasten war nämlich eine gewohnte Ansicht im Rathaus, denn im Rathaus befand sich ein ähnlicher »eiserner Wagen für glühende Kohlen, so daß der in dem Feuerprobenbild im Vordergrund gezeigte, auch eine Anspielung auf den Gerichtsraum des Rathauses sein könnte « ${ }^{25}$. Man darf in diesem Zusammenhang auch nicht vergessen, daß im Gegensatz zu den kleinen Johannestafeln van der Weydens und Memlings [Abb. 3 u. 5] und insbesondere zu der Miniaturdarstellung von Roussillon [Abb.7] diese Figuren nicht winzig klein, sondern sehr groß zur Darstellung gebracht wurden. Die Gesamthöhe der Gemälde beträgt $324 \mathrm{~cm}$, deren Hälfte, also $162 \mathrm{~cm}$, entspricht mehr oder weniger dem mittleren Wert der Körperhöhe eines erwachsenen Menschen in dieser Zeit, wie Schöne verdeutlicht:

»Daß die kleine Verbrennungsszene des Hintergrundes nicht so miniaturhaft ausgeführt ist, wie sie es als Gegenstand eines einzelnen kleinen Bildes des Meisters wäre, ist hier nur als Verdienst zu werten; denn wir haben nicht zwei ins Riesenhafte ausgedehnte Miniaturen vor uns, sondern große Bilder mit lebensgroßen Gestalten, die der Größe ihres Formats in allem, auch in ihrer Malweise, Rechnung tragen. $\aleph^{26}$

Im Gegensatz zu vielen niederländischen Gemälden und auch im Gegensatz zu den ikonographisch herangezogenen Bildern sind bei Bouts sowohl die räumlichen Dimensionen als auch die Figuren lebensgroß. Der Betrachter der Rathausbilder steht daher 
Personen und Dingen in einer möglichen Welt gegenüber. Vor diesem Hintergrund kann zusammenfassend festgehalten werden, daß Bouts zwei bestehende Bildformeln übernommen hat, die eine gemeinschaftsstiftende Funktion besitzen, um diese miteinander zu kombinieren. Erstens das `Theaterpublikum im Bild, das in Gemeinschaft der inszenierten Erzählung gegenübersteht, ohne in die Handlung involviert zu sein. Zweitens die gemeinschaftsbildende Funktion einer aus dem Bild herausblickenden Figur, die sich an mehrere Betrachter vor dem Bild wendet, die im Fall von Cusanus die klerikale Bruderschaft in Brixen war. Indem Bouts beide Formen zusammenführt und diese zugleich in eine Darstellung mit lebensgroßen Figuren überführt, entsteht der bildliche Effekt, daß ein Betrachter, der sich in Gemeinschaft mit anderen Betrachtern vor dem Bild bewegt, in diesem Moment zugleich den Kreis des Publikums im Bild schließt.

\section{III}

Betrachtet man die beiden Rathausbilder zusammen, so wird deutlich, daß die vier Personen im Vordergrund gemeinsam die narrativen Szenen umrahmen [Abb. 1 u.2]. Links und rechts von der narrativen Handlung mit der Übergabe des Kopfes durch den Henker an die Gräfin auf der ersten Tafel sind die zwei männlichen Figuren gelängt gemalt. In gleicher Weise werden am Rand des zweiten Bildes zwei Personen in einer leichten Rückenansicht dargestellt. Die linke Rückenfigur mit dem angewinkelten Ellenbogen auf der linken Tafel und die rechte Rückenfigur auf der rechten Tafel, deren Gesicht im Profil dargestellt ist, rahmen gemeinsam über die Bildgrenzen hinweg die Szenen. Die im Profil dargestellte, reich gekleidete adlige Figur rechts befindet sich auf der gleichen Raumebene wie die linke Rückenfigur, die mit ihrem angewinkelten Arm den Bildraum nach vorne durchbricht, und korrespondiert in ihrer Länge mit der hohen Säule des Thrones. Somit übernehmen die vier männlichen Figuren, die im Vordergrund der Gemälde situiert sind, die Funktion einer kompositorischen Unterteilung sowie einer farblichen Rahmung, die die rhythmische Komposition der Figuren im Raum widerspiegelt. Otto Pächt vergleicht die um die dramatischen Szenen versammelten Figuren mit gotischen Pfeilern, was jedoch nicht positiv aufgefaßt, sondern als negatives Kennzeichen der Bilder kritisiert wird:

»Die leichte Bewegtheit im Zentrum der Komposition geht jedoch unter in der Parallelisierung gehäufter Figurenvertikalen. Perspektivisches Größerwerden in der Nähe steigert 
sich zu einem faktischen Größersein der Vordergrundsfiguren, die wie überlängte gotische Pfeiler emporschießen. Der maßlos gesteigerte Vertikalismus intensiviert die Isolierung der Handlungsteilnehmer. Hand in Hand mit der physischen geht die psychische Isolierung. ${ }^{27}$

Indem Pächt die als gotisch charakterisierte Längung der Figuren mit einer sowohl physischen wie psychischen Isolierung verknüpft, nimmt er drei zentrale Kritiken auf, die in Bezug auf die Rathausbilder von Bouts formuliert wurden. Neben der Teilnahmslosigkeit der Löwener Bürger und ihrer in die Länge gezogenen Vertikalität wurden von der Forschung besonders die als zufällig und disparat betrachtete Komposition sowie die Steifheit der Figuren kritisiert, die im Gegensatz zur Bewegung in der Handlung steht. Diese jedoch haben ikonisch gesehen die Aufgabe, gerade in ihrer statischen Ruhe die bewegte Erzählung einzurahmen. Zugleich sind die Plätze und Positionierungen dieser versammelten Figuren als kreisförmige Versammlung inszeniert, in die der Betrachter auf unterschiedliche Weise eintreten kann. Der Betrachter kann auf den Leichnam und auf den Feuerkasten herunterschauen, wie es die versammelten Figuren im Gemälde tun könnten. Der Betrachter kann sich in Gemeinschaft mit den anderen Betrachter vor den Gemälden hin und her bewegen, wie wenn er einem Theaterschauspiel beiwohnen würde. Und nicht zuletzt wird der Betrachter dabei 


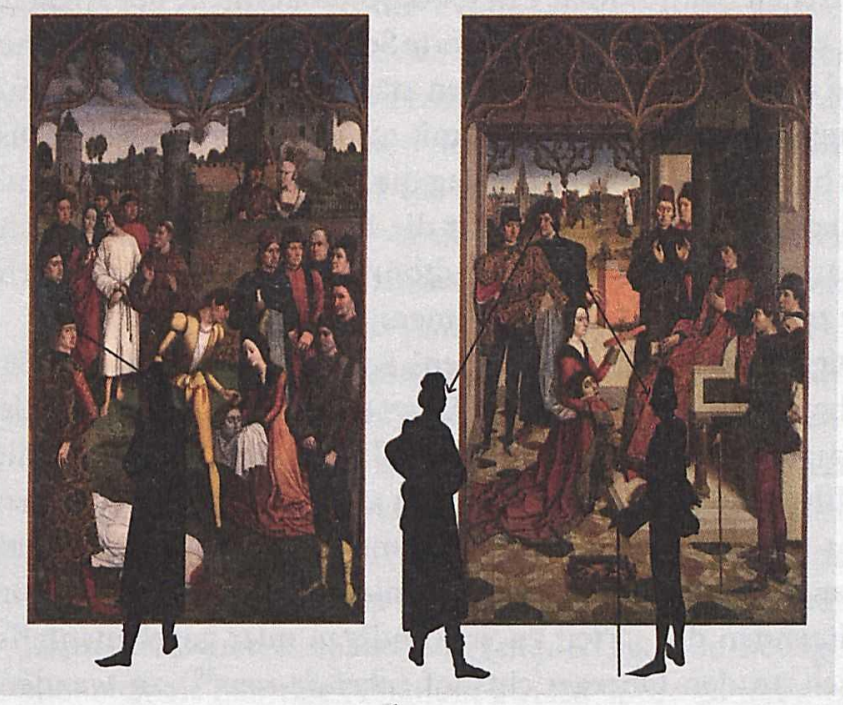

stets sowohl von der zeigenden Figur mit Goldkette im Hintergrund als auch von der Figur im Vordergrund, dessen angewinkelter Arm als trompe-l'œil die Bildfläche durchbricht, stets angeblickt. Diese zwei Figuren legen nahe, daß der Betrachter direkt adressiert wird und zugleich eingeladen wird, in das Bild einzutreten. Denn stellt man sich in die Reihe mit der linken Rückenfigur der linken Tafel oder der rechten Figur auf der rechten, die im Profil und in einer leichten Rückenansicht dargestellt ist, schließt man in diesem Moment mit den anderen dargestellten unbeteiligten Zuschauern den Kreis um die narrativen Szenen im Mittelfeld, wie anhand eines Schemas mit fiktiven Betrachtern ersichtlich wird [Abb. 9].

Bouts gelingt es auf diese Weise, in den Rathausgemälden zwei verschiedene Bildkonzepte miteinander zu vereinen. Indem der Betrachter vor den räumlich in Distanz gerückten Szenen steht, befindet er sich vor dem Bild und nimmt zugleich die Position eines distanzierten Auges ein, das über die dargebotenen Szenen thront. Betritt der Betrachter jedoch den Kreis des Publikums, das indifferent die narrativen Szenen umrahmt, befindet er sich nicht vor, sondern im Bild oder steht gemeinsam mit den versammelten Figuren der Erzählung gegenüber. Zentral bei den Rathausgemälden von Löwen ist dabei, daß es sich bei den adressierten Betrachtern vor dem Bild weder um ein Theaterpublikum noch um eine mönchische Bruderschaft, sondern um eine juridische Gemeinschaft handeln kann. Versetzt man die Rathausgemälde von Bouts in den juridischen Kontext 
der brabantischen Stadt Löwen um 1500, so besaß nicht der Richter, sondern das körperschaftlich organisierte Schöffentum die juridische Aufgabe und Macht des Urteilens. Den städtischen Schöffen, die in den frühneuzeitlichen Niederlanden mit scabini, schepenen, eskevins oder judices bezeichnet wurden ${ }^{28}$, oblag die Strafrechtsprechung und das zivile Recht. ${ }^{29}$ Raymond Byl fasst die Funktionen der Schöffen, die allein dafür zuständig waren, Stadtbürger vor Gericht zu holen und Urteile zu fällen, wie folgt zusammen:

»Die Rolle der [brabantischen] Schöffen in juridischer Sache bestand darin, die Klagen entgegenzunehmen, die Parteien und die Zeugen vorzuladen, den Rechtsfall mit Hilfe von Zeugen einzuführen und die Untersuchungen zu leiten. Anschließend versammelte sich das Tribunal, um nach den 'Beratungen sitzenden das Urteil zu verkündigen oder gegebenenfalls sich an den Obergerichtshof (chef-de-sens ${ }^{30}$ ) zu wenden. Manchmal setzten die Schöffen sogar die Höhe des vom Angeklagten zu bezahlenden Betrages fest. ${ }^{31}$

Die Schöffen in Löwen waren daher nicht nur Verwalter der Stadt, sondern bildeten auch die höchste Rechtsinstanz, soweit die Fälle nicht durch Korporationsreglements der einzelnen Zünfte, der Kirchen oder der Universität abgedeckt waren. Der villicus und jeweils zwei Schöffen übten auch die Notarsfunktion in der Stadt aus, so daß sie offizielle Zeugen und Kontrolleure aller größeren zivilrechtlichen Aktionen waren. Als Chef der Polizei durfte der villicus auch nur auf Antrag oder mit Erlaubnis der Schöffen Stadtbürger verhaften und dem Gericht zuführen. In diesem Fall übernahmen die Schöffen hierbei die Rolle des heutigen Staatsanwaltes. Die Schöffen konnten daher auch aufgrund des Verdachts auf einen Rechtsbruch Ermittlungen einleiten, ohne daß eine Anklage erhoben wurde. Vorsitzender des Schöffengremiums ist der Mayer (mayeur oder villicus), der vom Herzog eingesetzte Repräsentant der Macht, der die Ansprüche des Landesherren vertritt. Im 15. Jahrhundert bekommt er einen Stellvertreter für die Zeit seiner Abwesenheit von der Stadt. Er ist allerdings nicht ein Richter im eigentlichen Sinne, sondern nur der Verhandlungsleiter des Schöffengerichts. Allein den Schöffen war es gestattet, als gemeinschaftliches Gremium die Verbrechen im Gerichtsraum zu deuten und Urteile zu fällen. Diese Tätigkeit der Hermeneutik im Rahmen der gerichtlichen Wahrheitsfindung war zur Zeit des Malers jedoch eine junge Erfindung. Im Gegensatz zur 
feudalen Rechtspraxis der Probe (épreuve), die Michel Foucault als regelgeleitetes Kräftemessen beschreibt und zu der auch das Gottesurteil im Gemälde Die Feuerprobe von Bouts zu zählen ist, sind es nun Schöffen und Richter, denen die Aufgabe der Wahrheitsfindung obliegt. Kennzeichnend für das System der Probe ist ihre Ähnlichkeit mit einem Duell, bei dem zwei Parteien gegeneinander antreten, wie dies auf der narrativen Ebene im Gemälde von Dieric Bouts zwischen der Gräfin als Anklägerin und dem Kaiser als Angeklagten geschieht. Das akkusatorische Verfahren im juridischen System der Probe zeichnet sich nach Foucault deshalb durch eine »binäre Struktur « ${ }^{32}$ aus, denn nur zwẹi Parteien, die beschuldigende und die angeschuldigte, sind im Spiel. Handelte es sich bei dem feudalen Rechtssystem der Probe (épreuve) um ein Verfahren, das das Eingreifen eines Dritten nicht gestattet, so rückt in dem neu aufkommenden inquisitorischen Rechtssystem (enquête) gerade die Figur des Dritten, »der sich als neutrales Element zwischen die anderen [stellt] und herauszufinden [versucht], wer von den beiden die Wahrheit sagt ${ }^{33}$, ins Zentrum der Szene. Der strukturelle Unterschied zwischen Probe und Untersuchung manifestiert sich nach Foucault in erster Linie auf der Ebene des Urteils:

»Das Urteil ist der Spruch eines Dritten, der sagt, was folgt: Einer hat Recht, weil er die Wahrheit gesagt hat; der andere hat Unrecht, weil er gelogen hat. Darum gibt es den Urteilsspruch im feudalen Recht nicht; die Aufteilung in Wahrheit und Irrtum zwischen den Kontrahenten spielt dort keine Rolle; es gibt nur Sieg oder Niederlage. $\aleph^{34}$

Für die Schöffen und die später urteilende Gewalt in der Gestalt des Richters stellt sich damit plötzlich ein neues Problem, nämlich, daß sie nun zu einer urteilenden Instanz geworden sind. Wenn nun diese als eine dritte juridische Instanz objektiv und neutral entscheidet, ob jemand als schuldig oder nicht schuldig erachtet wird, dann sind auch die Gerichtsverfahren durch andere Fragen geleitet. Diese faßt Foucault in Theorien und Institutionen des Strafvollzuges wie folgt zusammen:

»[Zur] Gesamtheit von Praktiken zählen die für die Untersuchung charakteristischen Fragen (Wer hat was getan? Ist die Tatsache allgemein bekannt? Wer hat es gesehen und kann das bezeugen? Was für Hinweise liegen vor und was für Beweise? Gibt es ein Geständnis?); die Phasen der Untersuchung (in denen jeweils die Tatsache begründet, der 
Schuldige festgestellt und die Umstände der Tat erfasst werden); die Personen der Untersuchung (derjenige, der verfolgt; derjenige, der zur Anzeige bringt; derjenige, der es gesehen hat; derjenige, der leugnet oder gesteht; derjenige, der richten und die Entscheidungen fällen muß). ${ }^{35}$

An dieser Stelle wird auch deutlich, daß das akkusatorische Verfahren auf diese Weise durch ein inquisitorisches ersetzt wurde, indem nun im Gegensatz zu einem dualen Verhältnis zwischen Ankläger und Angeklagtem plötzlich eine dritte Instanz ins Spiel kommt. Diese dritte Position einer unbeteiligten Beobachtung entwickeln die Rathausgemälden im Bild selbst, und genau innerhalb dieses juridischen Kontextes liegt die zentrale ikonische Neuerfindung von Bouts, die die Betrachter in die Bilder hineinziehen: Einerseits die des Eintretens ins Bild und andererseits die des Zurücktretens angesichts der ikonographisch entwickelten Bilderzählung eines juridischen Rechtsfalles. Diese im Bild angelegte Struktur ermöglicht es, als Betrachter einen Platz innerhalb der Gemeinschaft einzunehmen und zugleich in dieser Position distanziert dem narrativen Geschehen des exemplum gegenüber zu stehen. Mit Blick auf den juridischen Kontext nimmt man als Betrachter vor und im Bild innerhalb der Gemeinschaft des Schöffengremiums die Position eines juristischen Adressaten ein, der die sichtbar gemachten und zur Schau gestellte narrativen Fälle umkreist und in der mächtigen Rolle des Dritten das exemplum deutet sowie Urteile fällt. 


\section{Endnoten}

1 Vgl. Frans van Molle, «La justice d'Othon de Thierry Bouts. Sources d'Archives», in: Bulletin de l'Institut royal du patrimoine artistique, 2 (1958), S.7-17, hier: 9.

21467 wurde der Schreiner Reyner Cocx nach Antwerpen geschickt, um insgesamt vierundfünfzig große Holztafeln zu kaufen, die dafür vorgesehen waren, bemalt zu werden. Diese Holztafeln wurden per Schiff nach Löwen gebracht und oberhalb des Registerraumes (boven op de zale) versammelt und aufbewahrt. In diesem Raum sind auch heute die Kopien aus dem 19. Jahrhundert zu sehen. Zur Bemalung wurde eine Holztafel je einzeln in die Werkstatt von Bouts gebracht, und dies geschah das erste Mal zum Jahreswechsel 1470/71, wie die von Molle versammelten Quellen zeigen. Aus diesem Grund könnte die verloren gegangene Darstellung des Jüngsten Gerichts, an deren Aufstellung im Rathaus zu eben dieser Zeit gearbeitet wurde, zwischen 1468 und 1470 entstanden sein, vgl. ebd., S.7-17, hier: $12 \mathrm{f}$.

3 Vgl. ebd., S. 14.

4 Einen guten Einblick in die ikonographische Debatte ermöglicht Nicole VeroneeVerhaegen, "La Justice d'Othon de Thierry Bouts. Iconographie", in: Bulletin de l'Institut royal du patrimoine artistique, 1 (1958), S.22-30.

5 Vgl.Didier Martens, "Thierry Bouts et l'iconographie. Les choix du peintre, du soncepteur et du scommanditaire«, in: Catheline Périer-D’Ieteren (Hg.), Thierry Bouts. L'Euvre complet, Brüssel 2005, S.60-77, hier: S. 66.

6 Vgl. Paul Heiland, Dirk Bouts und die Hauptwerke seiner Schule. Ein stilkritischer Versuch, Straßburg 1902, S. 28.

7 Die Farben entsprechen der Kleiderordnung 15. und 16. Jahrhunderts, vgl. Elisabeth Vara, m...durch meister Niclaus den Nachrichter, ein stoltzen hüpschen man. Gedankensplitter zum Bild des Scharfrichters, in: Markus Steppan \& Helmut Gebhardt, Zur Geschichte des Rechts. Festschrift für Gernot Kocher zum 65. Geburtstag, Graz 2006, S.473-483.

8 Martens (Anm. 5), S. 66.

9 Vgl. ebd.

10 Vgl. Veronee-Verhaegen (Anm.4), S.22-30.

11 Diese Beobachtung verdanke ich Beate Fricke (Zürich).

12 Zur flämischen Buchmalerei und Dedikationen vgl.Georges Dogaer, The Flemisch Miniature-Painting in the 15th and 16th Centuries, Amsterdam 1983; Maurice Smeyers, Flämische Buchmalerei. Vom 8. bis zur Mitte des 16. Jahrhunderts. Die Welt des Mittelalters auf Pergament, Stuttgart 1999; Scot McKendrick, Flemish illuminated manuscripts, 1400-1550, London 2003; Elizabeth Morrison, Flemish Manuscript Painting in Context. Recent Research, Los Angeles 2006.

13 Martens (Anm. 5), S.67.

14 Nicolaus Cusanus, »Úber das Sehen Gottes (de visione Dei) oder: Über das Bild (De icona) «, in: ders., Philosophische und theologische Schriften, übers.v. Anton Scharpff \& Eberhard Döring, Wiesbaden 2005, S.233-282; zur bildtheoretischen Relevanz dieser Schrift vgl.Gottfried Boehm, Studien zur Perspektivität. Philosophie und Kunst in der Frühen Neuzeit, Heidelberg 1969, S.137-171; Norbert Herold, »Bild der Wahrheit-Wahrheit des Bildes. Zur Deutung des `Blicks aus dem Bild in der Cusanischen Schrift ,De visione Dei«, in: Volker Gerhard \& Norbert Herold (Hgg.), Wahrheit und Begründung, Königshausen 1985, S.71-98; sowie Holger Simon, «Bildtheoretische Grundlagen des neuzeitlichen Bildes bei Nikolaus von Kues», in: Concilium medii aevi, 7 (2004), S. 45-76.

15 Vgl. Michel de Certeau, "Nikolaus von Kues. Das Geheimnis eines Blickes«, in: Volker Bohn (Hg.), Bildlichkeit, Frankfurt am Main 1990, S.325-356.

16 Günter Schöne, Die Entwicklung der Perspektivbühne. Von Serlio bis Galli-Bibiena nach den Perspektivbüchern, Leipzig 1933, S.9.

17 Vgl. Heinz Kindermann, Theatergeschichte Europas, Salzburg 1966, Bd.I, S. $296 f$.

18 Ebd., S. 295.

19 Vgl. ebd., S. 438; zum Ablauf einer Moralität vgl. ebd., S. 436-440. 


\section{Endnoten/Abbildungsnachweis}

20 Vgl.Max Herrmann, Forschungen zur deutschen Theatergeschichte des Mittelalters und der Renaissance, Berlin 1914, S.278-291.

$21 \mathrm{Zu}$ den Rederijker in Löwen vgl. Jos Wils, Bijdragen tot de geschiedenis der Rederijkerskamer >Het Kersouwken te Leuven, Löwen 1912.

$22 \mathrm{Zu}$ den Rederijkers im Allgemeinen vgl. Kindermann (Anm. 17), Bd.II, S.211-238; und George Kernodle, From Art to Theatre. Form and Convention in the Renaissance, Chicago 1944, S. 111-129.

23 Vgl. Jean Jacquot (Hg.), Les Fêtes de la Renaissance. Congrès de l'Association Internationale des Historiens de la Renaissance, Bd.II, Brüssel u.a. 1960, S. 457.

$24 \mathrm{Vgl}$. Kindermann (Anm.17), Bd.I, S. 441 und Bd.II, S. 211.

25 Edward van Even, L'Ancienne Ecole de Peinture de Louvain, Brüssel u.a. 1870, S. 198, Anm. 1.

26 Wolfgang Schöne, Dieric Bouts und seine Schule, Berlin, 1938, S. 115.

27 Otto Pächt, Altniederländische Malerei. Von Rogier van der Weyden bis Gerard David, München 1994, S. 140.

28 Vgl. Raymond Byl, Les juridictions scabinales dans le duché de Brabant. Des origines à la fin du XVe siècle, Brüssel 1965, S. 66.

29 Zur These, daß die Gemälde sich an die Schöffen richten, vgl. Claudia Blümle, Der Zeuge im Bild. Zur Konstitution des modernen Rechtsraumes bei Dieric Bouts, München 2009.

30 Zum Obergerichtshof im brabantischen 15. Jahrhundert vgl. Philippe Godding, "Appel et recourse à chef de sens en Brabant aux XIVe et XVe siècles. Wie hoet heeft, die heeft beroep", in: The Legal History Review, 65/3 (1997), S. 281-297.

31 Byl (Anm. 28), S. 242 (Übers. C. B.).

32 Vgl. Michel Foucault, "Die Wahrheit und die juristischen Formen «, in: ders., Schriften, Frankfurt am Main 2001-2005, Bd.II, S. 669-792, hier: 709.

33 Ebd., S.713.

34 Ebd.

35 Michel Foucault, »Theorien und Institutionen des Strafvollzuges», in: Foucault (Anm.32), Bd.II., S. 486-490, hier: 488.

\section{Abbildungsnachweis}

1 Dieric Bouts, Die Gerechtigkeit Ottos III., Die Hinrichtung des Unschuldigen, (1473-1482), Öl auf Holz, $324 \times 183 \mathrm{~cm}$, Brüssel: Musée des Beaux-Arts, aus: Brigitte de Patoul \& Roger Van Schoute (Hgg.), Les Primitifs flamands et leur temps. La Renaissance du livre, Tournai 2000, S. 398.

2 Dieric Bouts, Die Gerechtigkeit Ottos III., Die Feuerprobe (1471-1473), Öl auf Holz, $324 \times 183 \mathrm{~cm}$, Brüssel: Musée des Beaux-Arts, aus: Hans Belting \& Christiane Kruse, Die Erfindung des Gemäldes, München 1994, Tafel 157, Abb. 213.

3 Rogier van der Weyden, Die Enthauptung Johannes' des Täufers, rechter Flügel des Johannesaltars (um 1446-1453), Öl auf Holz, $77 \times 48 \mathrm{~cm}$, rechter Flügel, Berlin: Gemäldegalerie, aus: Robert Suckale, Rogier van der Weyden. Die Johannestafel. Das Bild als stumme Predigt, Frankfurt am Main 1995, Falttafel.

4 Dieric Bouts, Die Gerechtigkeit Ottos III., Die Hinrichtung des Unschuldigen, (1473-1482), Öl auf Holz, $324 \times 183 \mathrm{~cm}$, Brüssel: Musée des Beaux-Arts, aus: Brigitte de Patoul \& Roger Van Schoute (Hgg.), Les Primitifs flamands et leur temps. La Renaissance du livre, Tournai 2000, S. 398.

5 Hans Memling, Die Enthauptung Johannes des Täufers, linker Flügel des Triptychons der Mystischen Hochzeit der Hl. Katharina von Alexandrien (um 1479), Öl auf Holz, $172 \times 79 \mathrm{~cm}$, Brügge: Memlingmuseum, aus: Hans Belting \& Christiane Kruse, Die Erfindung des Gemäldes, München 1994.

6 Dieric Bouts, Die Gerechtigkeit Ottos III., Die Feuerprobe (1471-1473), Ol auf Holz, $324 \times 183 \mathrm{~cm}$, Brüssel: Musée des Beaux-Arts, aus: Hans Belting \& Christiane Kruse, Die Erfindung des Gemäldes, München 1994, Tafel 157, Abb. 213. 


\section{Abbildungsnachweis}

7 Meister Girart de Roussillon, Dedikation eines Manuskriptes für Philippe den Guten (1462), Miniatur in Cy nous dit, Brüssel: Bibliothèque royale de Belgique, aus: Anna Rapp Buri \& Monica Stucky-Schürer, Burgundische Tapisserien, München 2001, S. 128, Abb. 117.

8 Schema aus: Michel Certeau, "Nikolas von Kues. Das Geheimnis eines Blickes«, in: Volker Bohn (Hg.), Bildlichkeit, Frankfurt am Main 1990, S.325-356, S. 351.

9 Dieric Bouts, Die Gerechtigkeit Ottos III. (1471-1482), Ol auf Holz, $324 \times 183 \mathrm{~cm}$, Brüssel: Musée des Beaux-Arts. Schema mit Betrachterfiguren von C. B. 